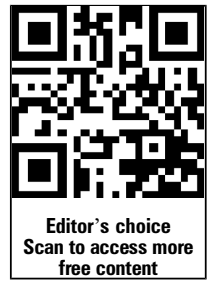
published online only. To view please visit the journal online (http://dx.doi.org/10.1136/ heartjnl-2013-305167).

${ }^{1}$ Inserm U1046, Physiologie \& Médecine Expérimentale, Cœur et Muscles, Université Montpellier-1 \& 2, Montpellier, France

${ }^{2}$ ADInstruments Limited Oxford, UK

${ }^{3}$ Service de Cardiologie, Hôpital Trousseau, Tours, France

\section{Correspondence to} Dr Jérôme Thireau, Inserm U1046, Physiologie \& Médecine Expérimentale, Cœur et Muscles, CHU Arnaud de Villeneuve, 371 avenue doyen G. Giraud, Montpellier 34295 , France;

jerome.thireau@inserm.fr

SK and SR contributed equally to this study.

Received 28 October 2013 Revised 29 January 2014 Accepted 25 February 2014 Published Online First 25 March 2014

\section{SLinked}

- http://dx.doi.org/10.1136/ heartjnl-2014-305503

\section{CrossMark}

To cite: Thireau J, Karam S, Roberge $S$, et al. Heart 2014;100:833-841.

\title{
$\beta$-Adrenergic blockade combined with subcutaneous B-type natriuretic peptide: a promising approach to reduce ventricular arrhythmia in heart failure?
}

\author{
Jérôme Thireau, ${ }^{1}$ Sarah Karam, ${ }^{1}$ Stéphanie Roberge, ${ }^{1}$ Julien Roussel, ${ }^{1}$ \\ Franck Aimond, ${ }_{1}^{1}$ Cécile Cassan, ${ }^{1}$ Arnaud $\mathrm{Gac}^{2}{ }^{2}$ Dominique Babuty, ${ }^{3}$ \\ Jean-Yves Le Guennec, ${ }^{1}$ Alain Lacampagne, ${ }^{1}$ Jérémy Fauconnier, ${ }^{1}$ Sylvain Richard ${ }^{1}$
}

\section{ABSTRACT}

Aims Clinical studies failed to prove convincingly efficiency of intravenous infusion of neseritide during heart failure and evidence suggested a pro-adrenergic action of B-type natriuretic peptide (BNP). However, subcutaneous BNP therapy was recently proposed in heart failure, thus raising new perspectives over what was considered as a promising treatment. We tested the efficiency of a combination of oral $\beta 1$-adrenergic receptor blocker metoprolol and subcutaneous BNP infusion in decompensated heart failure.

Methods and results The effects of metoprolol or/and BNP were studied on cardiac remodelling, excitation-contraction coupling and arrhythmias in an experimental mouse model of ischaemic heart failure following postmyocardial infarction. We determined the cellular and molecular mechanisms involved in antiremodelling and antiarrhythmic actions. As major findings, the combination was more effective than metoprolol alone in reversing cardiac remodelling and preventing ventricular arrhythmia. The association of the two molecules improved cardiac function, reduced hypertrophy and fibrosis, and corrected the heart rate, sympatho-vagal balance (low frequencies/high frequencies) and ECG parameters ( $P$ to $R$ wave interval (PR), QRS duration, QTc intervals). It also improved altered $\mathrm{Ca}^{2+}$ cycling by normalising $\mathrm{Ca}^{2+}$-handling protein levels (S100A1, SERCA2a, RyR2), and prevented pro-arrhythmogenic $\mathrm{Ca}^{2+}$ waves derived from abnormal $\mathrm{Ca}^{2+}$ sparks in ventricular cardiomyocytes. Altogether these effects accounted for decreased occurrence of ventricular arrhythmias.

Conclusions Association of subcutaneous BNP and oral metoprolol appeared to be more effective than metoprolol alone. Breaking the deleterious loop linking BNP and sympathetic overdrive in heart failure could unmask the efficiency of BNP against deleterious damages in heart failure and bring a new potential approach against lethal arrhythmia during heart failure.

\section{INTRODUCTION}

A major source of preventable cardiac death in heart failure is the ventricular arrhythmia (VA). ${ }^{1} \mathrm{VA}$ involves ventricular remodelling and alterations of $\mathrm{Ca}^{2+}$ homeostasis following chronic adrenergic overactivation. ${ }^{2}$ We showed that B-type natriuretic peptide (BNP) promotes $\mathrm{Ca}^{2+}$-dependent VA via a similar mechanism. ${ }^{3}$ The clinical advantages of the use of recombinant intravenous BNP nesiritide are also subject to debate despite its favourable haemodynamic effects. ${ }^{4}$ One explanation could be that intravenous BNP further compromises autonomic regulation in heart failure ${ }^{6}$ via a pro-adrenergic action unmasking its beneficial effects. ${ }^{3} 78$

Subcutaneous BNP administration has recently yielded promising results in systolic heart failure. ${ }^{9} \mathrm{We}$ thus aimed to determine the effects of a combination of the selective $\beta 1$-adrenergic blocker (BB) metoprolol associated with subcutaneous BNP infusion in a mouse model of decompensated heart failure. Until now, no study in human or animal had specifically tested this combination and investigated cellular and molecular mechanisms. This combination could associate the efficiency of the main antiarrhythmic in use, particularly in postmyocardial ischaemic heart failure with a reduced $\mathrm{LV} \mathrm{EF}{ }^{10}$ and unmasks the beneficial antifibrotic, antiapoptotic and antihypertrophic properties of BNP by abolishing the BNP-associated adrenergic effects.

We showed that the combination was more effective than metoprolol or BNP alone in preventing cardiac remodelling and VA, with better benefits on cardiac morphology, function and $\mathrm{Ca}^{2+}$ homeostasis.

\section{MATERIALS AND METHODS}

Please refer online supplement for methods which is available online.

\section{Study design}

Procedures conformed to European Parliament Directive 2010/63/EU and Council on the protection of animals were approved by our institutional animal research committee (CE-LR-0714). Seven-week-old male C57Bl/6 mice (Janvier, France) were randomly assigned to the following groups: (1) postmyocardial infarction (PMI); (2) PMI treated with BNP (BNP-PMI); (3) PMI treated with metoprolol (BB-PMI); (4) PMI treated with metoprolol and BNP (BB-BNP-PMI); and (5) sham-operated mice (Shams). For PMI, the coronary artery was ligated $1-2 \mathrm{~mm}$ beyond its emergence from the left atrium, under anaesthesia and cardiac monitoring (2\% isoflurane/ $\mathrm{O} 2$, Aerrane, Baxter). Buprenorphine $(0.3 \mathrm{mg} / \mathrm{mL})$ was injected for postoperative analgesia. ${ }^{3}$ Metoprolol (Sigma-Aldrich, $100 \mathrm{mg} / \mathrm{kg} /$ day) was administered in the drinking water. The mouse BNP (14-5-30A, 
American Peptide, USA) was subcutaneously administered at $0.03 \mu \mathrm{g} / \mathrm{kg} / \mathrm{min}$ for 14 days (Alzet-1002 osmotic pumps). ${ }^{3}$ Following in vivo investigations, heart was explanted after cervical dislocation for single-cell experiments. The time sequence of the protocol is shown in figure 1 .

\section{In vivo analysis}

Telemetric ECGs were recorded (DSI, USA) and analysed in respect of the Lambeth conventions. Heart rate variability, PR, QRS, corrected QT (QTc) intervals, short term variability of QT $\left(\mathrm{QT}_{\mathrm{STV}}\right)$ and spontaneous arrhythmias were analysed (EMKA, France). To test the contribution of long term anti-remodelling effect of treatments on arrhythmogenic susceptibility, the $\beta$-adrenergic catecholamine isoproterenol $(2.5 \mathrm{mg} / \mathrm{kg}$ intraperitoneal) was injected during and 4 weeks after the treatment. The triggering of sustained ventricular tachycardia (SVT) was monitored. At the same time-points, systolic, diastolic and mean arterial blood pressure were measured with a tail-cuff and pulse transducer (ML125/M NIBP System, ADInstruments, UK) in triplicate in conscious mice.

LV mass, LV shortening fraction, end-diastolic and endsystolic LV dimensions were measured by echocardiography (Vivid7Pro, GE Medical Systems, USA). ${ }^{3}$ Survival throughout experimental protocol was followed (see online supplementary table S1 and S4).

\section{Autopsy and heart excision}

Autopsies were performed to verify pleural effusion and lungs congestion. The heart and lungs were excised and weighed, and the heart weight index determined (heart weight/body weight). Interstitial fibrosis was measured in $10 \mu \mathrm{m}$ thick transverse sections of hearts in the peri-infarcted area $(H \& E$ and Sirius red staining). Results indicated the area of Sirius red-stained tissue (percentage of total area of myocardial tissue).

\section{RNA extraction and RT-qPCR}

Total RNA was extracted from LV tissue using TRIzol, and treated with DNase I at $37^{\circ} \mathrm{C}$ for $30 \mathrm{~min}$. cDNA was synthesised using superscript II reverse transcriptase (Invitrogen, France). RT-qPCR was performed for myocardin-related transcription factor A (MRTF-A), serum response factor (SRF), $\mathrm{Na}^{+}-\mathrm{Ca}^{2+}$ exchanger (NCX1), sarcoplasmic reticulum (SR) $\mathrm{Ca}^{2+}$-ATPase (SERCA2a) and $\mathrm{Ca}^{2+}$-binding protein $\mathrm{S} 100 \mathrm{a} 1$ in duplicate (LightCycler, Roche, France) and normalised to GAPDH (eight mice/group).

\section{$\mathrm{Ca}^{2+}$ handling and patch-clamp}

Experiments were performed on freshly isolated LV myocytes. ${ }^{3}$ Cardiomyocytes were loaded with Indo-1AM $(10 \mu \mathrm{M}$, Invitrogen, France) and field-stimulated at $1.0 \mathrm{~Hz}$ with $1 \mathrm{~ms}$ current pulses (IonOptix system, USA). ${ }^{3}$ Indo-1 fluorescence emitted at 405 (F405) and $480 \mathrm{~nm}(\mathrm{~F} 480)$ were recorded to estimate intracellular $\mathrm{Ca}^{2+}$ level (F405 to F480 ratio) during a $30 \mathrm{~s}$ pacing period, followed by a $30 \mathrm{~s}$ rest period. Diastolic $\mathrm{Ca}^{2+}$ level, $\mathrm{Ca}^{2+}$ transient decay time (tau) and percentage of cells developing spontaneous $\mathrm{Ca}^{2+}$ waves were quantified during the rest period. $\mathrm{Ca}^{2+}$ sparks (frequency, amplitude and spatiotemporal characteristics) were recorded by following variations of fluorescence at $505 \mathrm{~nm}(\Delta \mathrm{F})$ divided by initial fluorescence at $505 \mathrm{~nm}(\mathrm{~F} 0)(\Delta \mathrm{F} / \mathrm{F} 0$, Fluo-4AM, $5 \mu \mathrm{M}, 1.5 \mathrm{~ms} /$ line; LSM510 Zeiss confocal microscope, 63X water-immersion objective, NA: 1.2). Cell volume was estimated using Z-stack ( $\mathrm{x}-\mathrm{y}$ projection, front view) image acquisition. ${ }^{3}$ Electrophysiological profiles of cardiomyocytes were investigated by current-clamp (action potential (AP)) and voltageclamp approaches $\left(\mathrm{I}_{\mathrm{Ca}, \mathrm{L}}, \mathrm{I}_{\mathrm{K}}\right)$ using the patch-clamp technique.

\section{$\mathrm{Ca}^{2+}$-handling proteins}

LV were homogenised into lysis buffer (0.3\% CHAPS, $1 \mu \mathrm{g} / \mathrm{mL}$ leupeptin, $1 \mu \mathrm{g} / \mathrm{mL}$ pepstatin and, in mM; HEPES 20, $\mathrm{KCl} \mathrm{40,}$ DTT 1, PMSF 1, EDTA 1, pH7.4) and centrifugated $(6000 \times g$, $5 \mathrm{~min}$ ). After protein quantification (DC Protein Assay, Bio-Rad), total proteins $(50 \mathrm{mg})$ were loaded on SDS-PAGE and transferred on nitrocellulose membrane (GE Healthcare). The membranes were blocked (Thermoscientific) and incubated with primary antibodies at $4^{\circ} \mathrm{C}$ overnight: SERCA2a (1:5000) (A010-20, Badrilla, UK), NCX1 (1:1000) (R3F1, Swant), ryanodine receptor RyR2 (1:1000) (Covalab, France) and PhosphoSer2808-RyR2 (1:1000) (A010-30, Badrilla), phospholamban (1:20 000) (A010-14, Badrilla) and PhosphoSer16-PLB (1:5000) (A010-12, Badrilla), and S100A1 (1:2500) (SP5355P, Acris antibodies, Germany). After incubation with secondary antibody $800 \mathrm{~nm}(1: 30$ 000): antirabbit (SERCA2a, PhosphoPLB, RyR2, PhosphoRyR2, S100A1) or antimouse (NCX1, PLB, GAPDH), membranes were washed and scanned (Odyssey, LI-COR Biosciences). Results were expressed relative to GAPDH (1:60 000) (ab8245, Abcam).

\section{STATISTICAL ANALYSIS}

All data are reported as means \pm SD (mean \pm SE for patch-clamp experiments). Statistical analyses were performed using GraphPad Prism and Origin Softwares. One-way ANOVA for
Figure 1 Time sequence of experimental procedure.

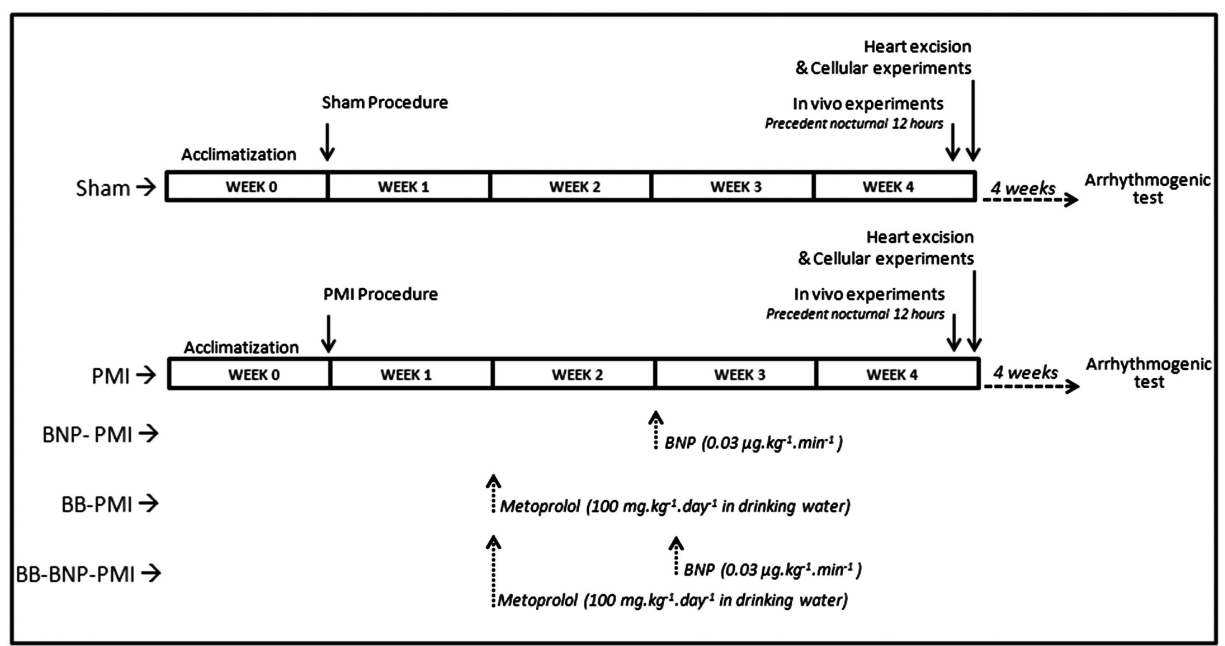


Table 1 Morphological and histological parameters

\begin{tabular}{|c|c|c|c|c|c|}
\hline & Sham & PMI & BNP-PMI & BB-PMI & BB-BNP-PMI \\
\hline Heart weight index $(\mathrm{mg} / \mathrm{g})$ & $4.9 \pm 0.2$ & $5.9 \pm 0.3 \ddagger$ & $6.2 \pm 0.1 \mp$ & $5.5 \pm 0.1 \dagger, \S$ & $5.3 \pm 1.1^{*}, \|, 9$ \\
\hline Pleural effusion (\%) & 0 & $58+$ & $57 \dagger$ & $69 \ddagger, \S$ & $33^{*}, \S, \#$ \\
\hline Lung congestion (\%) & 0 & $41 \dagger$ & $42 t$ & $69 \ddagger, \S$ & $33^{*}, \S, \#$ \\
\hline LV end-diastolic dimension (mm) & $25.4 \pm 0.5$ & $52.4 \pm 0.4 \ddagger$ & $47.1 \pm 0.3 \ddagger$ & $42.1 \pm 0.5 t, \S$ & $39.9 \pm 0.4 \dagger, \S$ \\
\hline LV shortening fraction (\%) & $58.9 \pm 1.3$ & $17.4 \pm 1.1 \ddagger$ & $17.5 \pm 0.8 \ddagger$ & $24.6 \pm 0.6 \dagger, \S$ & $29.6 \pm 0.9+, \|, \emptyset$ \\
\hline Collagen (\%) & $0.1 \pm 0.0$ & $5.2 \pm 1.8 \ddagger$ & $3.6 \pm 0.2 \ddagger, \S$ & $4.6 \pm 1.9 \neq$ & $2.4 \pm 1.5 t, \|, 9$ \\
\hline Cell volume $\left(10^{-5} \mathrm{~mm}^{3}\right)$ & $3.5 \pm 0.1$ & $5.5 \pm 0.5 \ddagger$ & $4.8 \pm 0.4 \dagger$ & $4.3 \pm 0.3^{*}, \S$ & $3.7 \pm 0.4 \|, 9$ \\
\hline
\end{tabular}

Table 2 ECG analysis

\begin{tabular}{|c|c|c|c|c|c|}
\hline & Sham & PMI & BNP-PMI & BB-PMI & BB-BNP-PMI \\
\hline \multicolumn{6}{|l|}{ ECG parameters } \\
\hline Heart rate (bpm) & $593 \pm 11$ & $630 \pm 12^{*}$ & $665 \pm 10 \dagger, \S$ & $536 \pm 12^{*}, \|$ & $539 \pm 12^{*}, \|$ \\
\hline QRS duration (ms) & $17.4 \pm 1.1$ & $32.8 \pm 1.4 \dagger$ & $33.1 \pm 1.1 \dagger$ & $33.5 \pm 1.2 \dagger$ & $28.2 \pm 0.9^{*}, \S, \emptyset$ \\
\hline QTc interval (ms) & $32.2 \pm 1.3$ & $51.3 \pm 1.4 \dagger$ & $59.5 \pm 1.6 \ddagger$ & $46.4 \pm 3.2 \dagger, \S$ & $45.7 \pm 2.4 \dagger, \S$ \\
\hline $\mathrm{QT}_{\mathrm{STV}}(\mathrm{ms})$ & $178 \pm 34$ & $362 \pm 31 \dagger$ & $454 \pm 45 \dagger$ & $285 \pm 33 \ddagger, \S$ & $149 \pm 55||, 9$ \\
\hline \multicolumn{6}{|l|}{ Heart rate variability } \\
\hline $\operatorname{LF}\left(\mathrm{ms}^{2}\right)$ & $0.052 \pm 0.005$ & $0.012 \pm 0.009 \dagger$ & $0.009 \pm 0.004 \dagger$ & $0.028 \pm 0.005 t, \S$ & $0.041 \pm 0.004^{*}, \|, 9$ \\
\hline $\mathrm{HF}\left(\mathrm{ms}^{2}\right)$ & $0.032 \pm 0.005$ & $0.028 \pm 0.009$ & $0.025 \pm 0.006$ & $0.032 \pm 0.005$ & $0.033 \pm 0.009$ \\
\hline LF to $H F$ & $1.62 \pm 0.11$ & $0.43 \pm 0.12 \dagger$ & $0.36 \pm 0.28 \dagger$ & $0.87 \pm 0.27^{*}, \S$ & $1.24 \pm 0.19^{*}, \|, 9$ \\
\hline SDNN (ms) & $14.9 \pm 2.4$ & $9.1 \pm 1.4^{*}$ & $5.8 \pm 1.3 \dagger$ & $13.5 \pm 2.1 \S$ & $18.1 \pm 2.1 \|, 9$ \\
\hline RMSSD (ms) & $5.7 \pm 0.9$ & $3.18 \pm 0.8^{*}$ & $3.54 \pm 1.1^{*}$ & $3.7 \pm 1.0^{*}$ & $3.6 \pm 1.1^{*}$ \\
\hline \multicolumn{6}{|l|}{$V A$} \\
\hline Number of VA & $21.3 \pm 4.2$ & $44.7 \pm 3.1 \dagger$ & $56.2 \pm 2.7 \dagger$ & $28.3 \pm 4.2 \S$ & $16.6 \pm 2.4 \|, 9$ \\
\hline \multicolumn{6}{|l|}{ SVT (\%) } \\
\hline During treatment & 8 & $50 t$ & $66 \ddagger, \S$ & $0 \|$ & $8 \|$ \\
\hline After treatment & 0 & $58 t$ & $58 t$ & $33 \S$ & $8 \|, 9$ \\
\hline
\end{tabular}

$\mathrm{BB}+\mathrm{BNP}$ improved heart rate variability and were more efficient than metoprolol alone to prevent variability of ventricular repolarisation and VA. Parameters estimated from $12 \mathrm{~h}$ nocturnal ECG: heart rate, QRS duration, corrected QT interval (QTC) and short term variability of QT (QT $\mathrm{T}_{\text {STV}}$ ). Heart rate variability analysis in the frequency- and time-domain with low frequencies (LF), high frequencies (HF) spectral power, LF to HF ratio, SD of all normal R-R intervals (SDNN) and square root of the mean square successive differences between successive normal R-R intervals (RMSSD). Number of spontaneous ventricular extrasystoles (VA) developed over $12 \mathrm{~h}$ ECG recording. Percentage of mice developing SVT following injection of isoproterenol $\left(2.5 \mathrm{mg} / \mathrm{kg}\right.$ intraperitoneal) during and assessed 4 weeks after treatment. ${ }^{*}, t, \neq p<0.05, p<0.01, p<0.001$ versus Sham; $\S$, $\| p<0.05, p<0.01$ versus PMl; $\uparrow$ $p<0.05$ versus $B B-P M l ; n=15 /$ group.

BB, $\beta 1$-adrenergic blocker; BNP, B-type natriuretic peptide; PMI, postmyocardial infarction; SVT, sustained ventricular tachycardia; VA, ventricular arrhythmia.

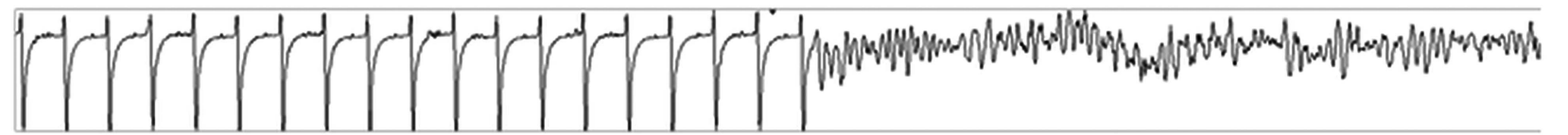

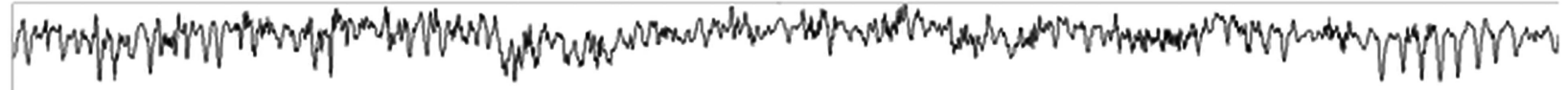

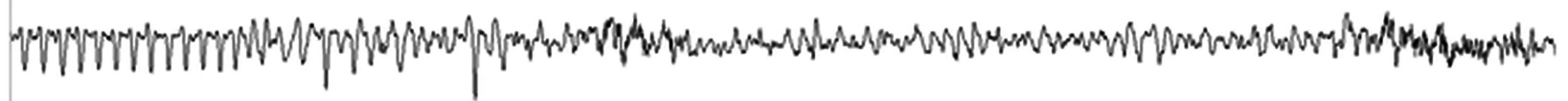

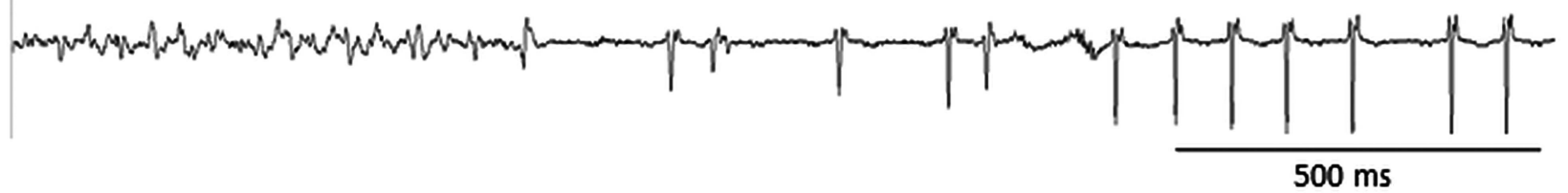

Figure 2 Arrhythmic events. Typical sustained ventricular tachycardia and ventricular fibrillation in postmyocardial infarction mice during isoproterenol challenge (2.5 mg/kg intraperitoneal). 


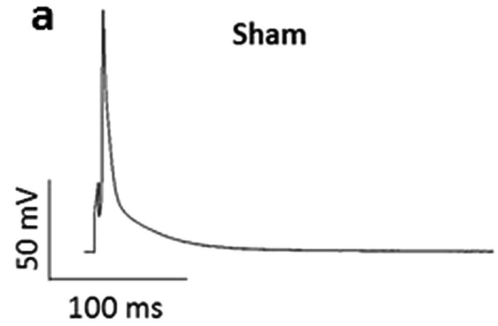

C
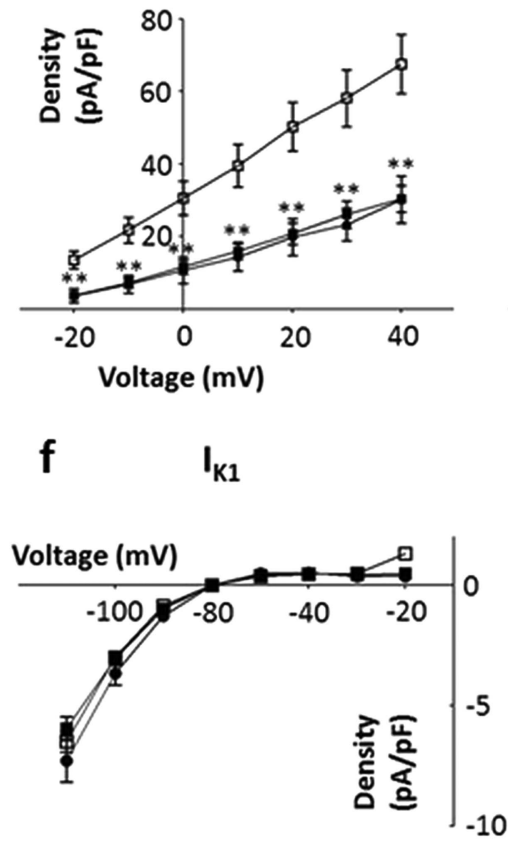
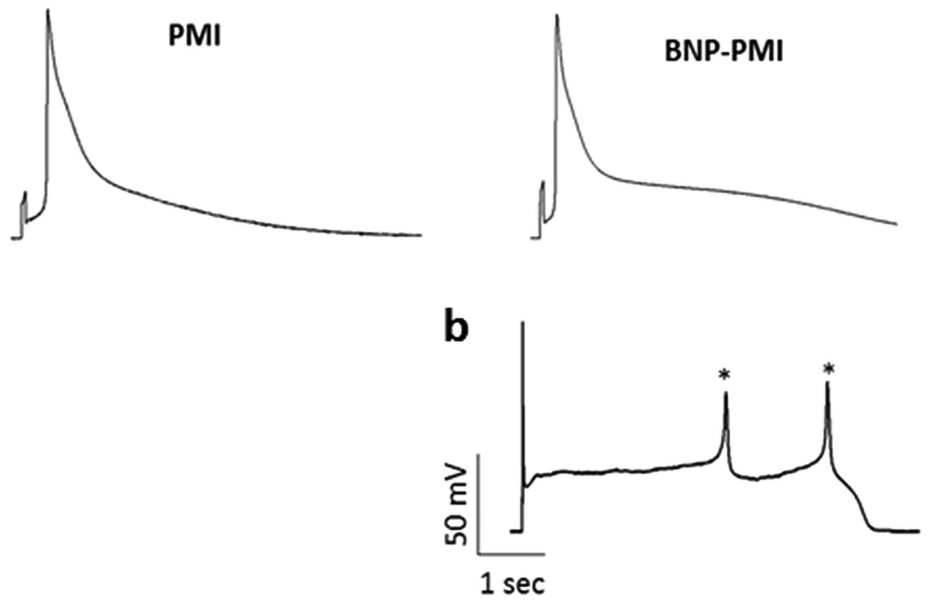

d

e

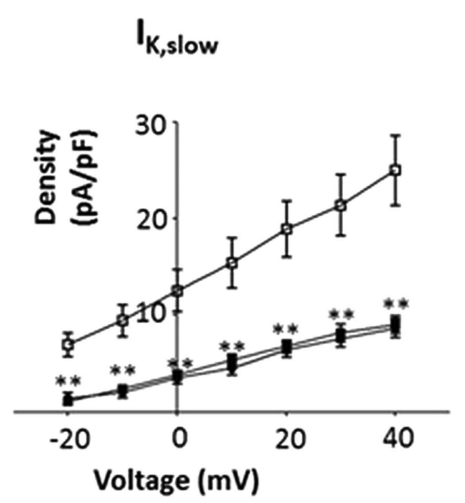

$\square$ Sham
PMI
BNP-PMI

Figure 3 Cellular electrophysiological profiles. Current clamp studies: (A) Representative action potentials were recorded from LV cardiomyocytes isolated from Sham, postmyocardial infarction (PMI) and B-type natriuretic peptide (BNP)-PMI mice. (B) Typical early afterdepolarisations obtained in BNP-PMI mice. Voltage clamp studies: Ionic currents in Sham (open square), PMI (filled square) and BNP-PMI mice (filled circle). (C) Mean \pm SE current/voltage relationships of the total voltage-gated $K^{+}$currents $\left(I_{\text {Kpeak }}\right),(D)$ transient outward $K^{+}$current $\left(I_{t o, F}\right),(E) I_{K s l o w}(F) I_{K 1}$ and $(G) I_{C a, L}$ ( $n=13-22$ cells). ${ }^{* *} p<0.01$ versus Sham.

multiple comparisons was used, followed by a parametric $t$ test with Bonferroni's correction. Percentage data were analysed by a $\chi^{2}$ test. A $\mathrm{p}$ value of 0.05 or less indicates a statistically significant difference.

\section{RESULTS}

\section{BNP reduced fibrosis and metoprolol improved cardiac} remodelling

MI mice exhibited heart failure with cardiac hypertrophy, increased LV end-diastolic dimensions, decreased LV shortening fraction and interstitial fibrosis (table 1; see online supplementary figure S1). The systolic, diastolic and mean arterial blood pressures were decreased (see online supplementary table S1). BNP did not improve morpho-functional remodelling after MI but reduced interstitial fibrosis (table 1, see online supplementary figure S1). In contrast, metoprolol reversed the increases of the heart weight index and LV end-diastolic dimensions in PMI, while pleural effusion and lung congestion worsened (table 1). Consistently, metoprolol reduced cell hypertrophy as confirmed by the quantification of MRTF-A and SRF mRNAs (see online supplementary table S2).

\section{$B B+B N P$ normalised morpho-functional parameters}

The BB+BNP combination was far more effective than metoprolol on cardiac hypertrophy, pleural effusion, lung congestion and LV end-diastolic dimensions (table 1). The combination reduced fibrosis and hypertrophy more efficiently than BB (table 1 , see online supplementary figure $\mathrm{S} 1$ ). $\mathrm{BB}$ and $\mathrm{BB}+\mathrm{BNP}$ had no 

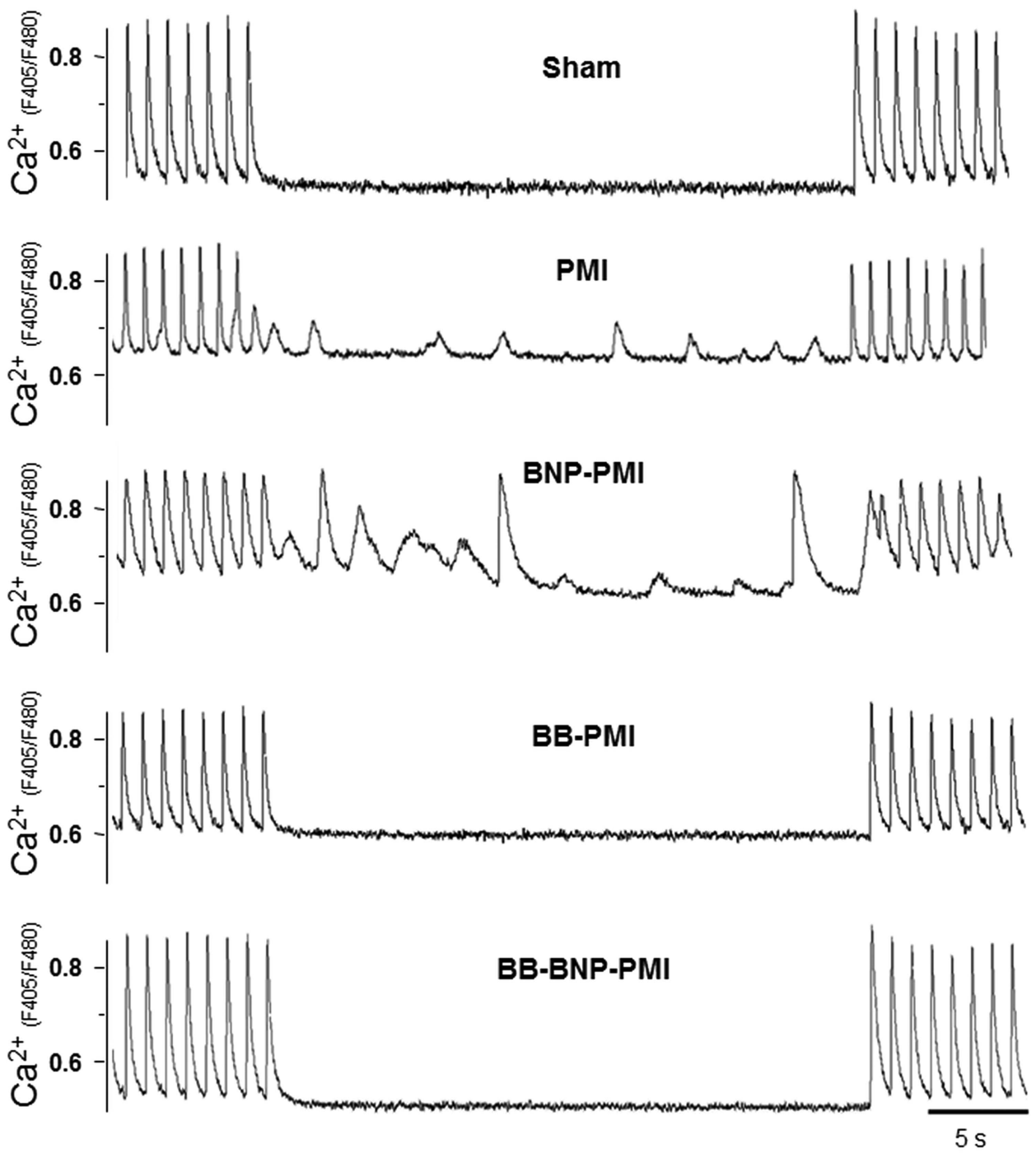

Electrical pacing

Figure $4 \mathrm{Ca}^{2+}$ transients. BB+B-type natriuretic peptide (BNP) decreased cellular susceptibility to arrhythmia by normalising $\mathrm{Ca}^{2+}$ homeostasis. Indo1-AM fluorescence ratio at 405 and $480 \mathrm{~nm}$ (F405 to F480) reflected intracellular Ca $\mathrm{Ca}^{2+}$ level variations during and after electrical pacing in LV cardiomyocytes. Postmyocardial infarction (PMI) and BNP-PMI developed abnormal spontaneous activities during non-stimulated period. BB, $\beta 1$-adrenergic blocker.

detrimental effect on the systolic blood pressure during treatment and conferred a persistent beneficial effect over time (see online supplementary table S1).

\section{BB+BNP corrected rhythm disturbances better than monotherapy}

PMI mice presented higher heart rate, and prolonged QRS and QTc intervals (table 2) when compared with Shams. The typical collapsed low frequencies to high frequencies ratio indicated that the sympathetic system was overactivated, as observed in heart failure. ${ }^{3}$ Moreover, the ventricular repolarisation instability expressed as the $\mathrm{QT}_{\mathrm{STV}}$ was increased (table 2, see online supplementary figure S2). All these parameters are wellrecognised prognostic markers for VA. PMI mice displayed a higher incidence of VA than Shams. BB and BB + BNP both normalised the heart rate and improved heart rate variability in PMI (table 2). The $\mathrm{QT}_{\mathrm{STV}}$ and the number of VA were also diminished (table 2, see online supplementary figure S2). Similar results have been reported in heart failure patients under
B-blockers. ${ }^{11}$ Overall, $\mathrm{BB}+\mathrm{BNP}$ was more effective than $\mathrm{BB}$ in correcting the heart rate variability and $\mathrm{QT}_{\mathrm{STV}}$ and in reducing VA (table 2).

Since catecholamines are a potent trigger of VA, mice were challenged with isoproterenol at two time-points. (1) During treatment, 33\% PMI and 66\% BNP-PMI mice developed SVT whereas Sham did not (table 2). BB and BB+BNP prevented SVT. (2) When all treatments were stopped, 58\% of PMI developed SVT, and 33\% triggered ventricular fibrillation (figure 2, table 2). In the BNP-PMI group, 60\% of mice developed SVT, and $33 \%$ developed ventricular fibrillation followed by cardiac death $\left(4 / 12, p<0.05, \chi^{2}\right.$ test vs PMI). The BB+BNP therapy remained highly beneficial in successfully preventing SVT $(8 \%)$ $\left(\chi^{2}\right.$ test, $\mathrm{p}<0.05$, table 2$)$.

\section{$\mathrm{BB}+\mathrm{BNP}$ normalised intracellular $\mathrm{Ca}^{2+}$ homeostasis}

VA could originate from AP lengthening and/or disturbed $\mathrm{Ca}^{2+}$ handling. Whereas AP shape was altered in PMI and BNP-PMI, AP duration and underlying currents $\left(\mathrm{Ca}^{2+}\right.$ and $\left.\mathrm{K}^{+}\right)$were 
Table 3 Intracellular $\mathrm{Ca}^{2+}$ signalling in LV cardiomyocytes, $\mathrm{Ca}^{2+}$ transients and cell shortening

\begin{tabular}{|c|c|c|c|c|c|}
\hline & Sham & PMI & BNP-PMI & BB-PMI & BB-BNP-PMI \\
\hline \multicolumn{6}{|l|}{$\mathrm{Ca}^{2+}$ transient (Indo1-AM) } \\
\hline Amplitude (F405 to F480) & $5.24 \pm 0.18$ & $4.47 \pm 0.25^{*}$ & $4.12 \pm 0.09 \dagger$ & $5.3 \pm 0.11 \S$ & $5.81 \pm 0.16^{*}, \|, 9$ \\
\hline$\tau(\mathrm{ms})$ & $294 \pm 21$ & $371 \pm 15^{*}$ & $361 \pm 17^{*}$ & $312 \pm 18 \S$ & $262 \pm 19 \|, \#$ \\
\hline SR-Ca ${ }^{2+}$ content ( $F 405$ to $\left.F 480\right)$ & $9.3 \pm 0.4$ & $7.2 \pm 0.1^{*}$ & $6.4 \pm 0.3 \dagger, \S$ & $8.6 \pm 0.3 \S$ & $9.6 \pm 0.2 \|, \#$ \\
\hline Diastolic $\mathrm{Ca}^{2+}$ level (F405 to F480) & $0.55 \pm 0.01$ & $0.65 \pm 0.02 \dagger$ & $0.71 \pm 0.01 \ddagger$ & $0.51 \pm 0.02 \|$ & $0.50 \pm 0.01 \|$ \\
\hline Sarcomere shortening (\%) & $9.65 \pm 0.32$ & $7.21 \pm 0.35 t$ & $7.06 \pm 0.34 \dagger$ & $9.16 \pm 0.31 \S$ & $10.41 \pm 0.29 \|, \#$ \\
\hline Arrhythmic cells (\%) & $7.1 \pm 5.4$ & $72.3 \pm 14.4 \ddagger$ & $62.9 \pm 9.7 \ddagger$ & $24.4 \pm 3.3^{*}, 9$ & $11.6 \pm 4.9 \eta, \#$ \\
\hline \multicolumn{6}{|l|}{$\mathrm{Ca}^{2+}$ sparks (Fluo4-AM) } \\
\hline 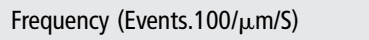 & $1.05 \pm 0.05$ & $5.12 \pm 0.23 \dagger$ & $6.34 \pm 0.13 \dagger, \S$ & $1.84 \pm 0.14^{*}, \|$ & $1.04 \pm 0.279, \#$ \\
\hline Amplitude $(\Delta \mathrm{F} / \mathrm{F} 0)$ & $0.58 \pm 0.01$ & $0.49 \pm 0.02^{*}$ & $0.41 \pm 0.01 \dagger, \|$ & $0.54 \pm 0.01 \S$ & $0.61 \pm 0.019, \#$ \\
\hline FDHM (ms) & $14.3 \pm 0.4$ & $23.7 \pm 1.2 \dagger$ & $34.3 \pm 2.1 \dagger, \|$ & $16.9 \pm 1.7^{*}, \S$ & $11.1 \pm 1.19, \#$ \\
\hline FWHM (ms) & $1.34 \pm 0.02$ & $1.67 \pm 0.05^{*}$ & $2.10 \pm 0.06 t$ & $1.50 \pm 0.05$ & $1.59 \pm 0.04$ \\
\hline
\end{tabular}

comparable between these two groups (figure 3, see online supplementary table S3). So we looked for differences in intracellular $\mathrm{Ca}^{2+}$ level that could trigger afterdepolarisations (figure $3 \mathrm{~B}$ ). In PMI, $\mathrm{Ca}^{2+}$ transient was altered with smaller amplitude and slower decay kinetics together with reduced $\mathrm{SR}-\mathrm{Ca}^{2+}$ content and higher diastolic $\mathrm{Ca}^{2+}$ levels than in Shams (figure 4, table 3 ). These changes accounted for, respectively, the decrease in sarcomeres shortening and the triggering of spontaneous irregular $\mathrm{Ca}^{2+}$ waves (figure 4, table 3). Chronic BNP worsened all

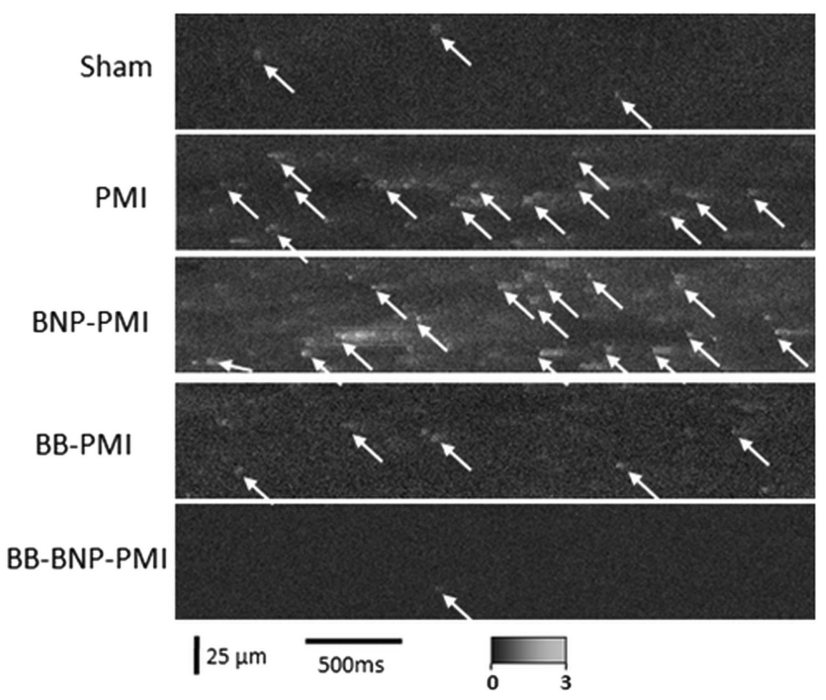

Figure $5 \mathrm{Ca}^{2+}$ sparks. BB+B-type natriuretic peptide (BNP) prevented $\mathrm{Ca}^{2+}$ leakage from RyR2. Representative variations of fluorescence at $505 \mathrm{~nm}$ (F505) during line scan acquisition in Fluo-4 AM-loaded cardiomyocytes from Sham, postmyocardial infarction (PMI), BNP-PMI, BB-PMI and BB-BNP-PMI animals. Each sporadic elevation of fluorescence (indicated by white arrows) represents a $\mathrm{Ca}^{2+}$ spark due to spontaneous activation of ryanodine receptors. Whereas Sham cells presented few $\mathrm{Ca}^{2+}$ sparks, PMI presented an increased sparks frequency, reflecting a severe $\mathrm{Ca}^{2+}$ leakage from the reticulum sarcoplasmic. BB and, to a larger extent, BB-BNP reduced $\mathrm{Ca}^{2+}$ sparks frequency. $B B, \beta 1$-adrenergic blocker. these alterations and irregular $\mathrm{Ca}^{2+}$ waves persisted (figure 4, table 3). In contrast, both $\mathrm{BB}$ and $\mathrm{BB}+\mathrm{BNP}$ improved $\mathrm{Ca}^{2+}$ homeostasis and reduced the number of pro-arrhythmogenic waves (table 3 ). Nevertheless, $\mathrm{BB}+\mathrm{BNP}$ was more effective than $\mathrm{BB}$ alone to reduce $\mathrm{Ca}^{2+}$ sparks frequency and occurrence of $\mathrm{Ca}^{2+}$ waves (figure 4 and figure 5; table 3 ). Thus, the beneficial effects of $\mathrm{BB}+\mathrm{BNP}$ on $\mathrm{Ca}^{2+}$ cycling could explain its antiarrhythmic advantage.

\section{$\mathrm{BB}+\mathrm{BNP}$ normalised changes in $\mathrm{Ca}^{2+}$-handling proteins}

The alterations of $\mathrm{Ca}^{2+}$ homeostasis in heart failure resulted from modifications of $\mathrm{Ca}^{2+}$-handling proteins as we observed for SERCA2a, S100A1 and NCX in PMI (table 4, see online supplementary figure S3). In addition, PLB phosphorylation (Ser16) was decreased while RyR2 phosphorylation (Ser2808) was increased (table 4). BNP had no major effect on SERCA2a, NCX, or the phosphorylation of PLB and RyR2, but it further reduced S100A1 expression (table 4, see online supplementary figure S3). This additional reduction of S100A1 accounted for the higher $\mathrm{Ca}^{2+}$ sparks frequency in BNP-PMI. ${ }^{12}{ }^{13}$ In contrast, $\mathrm{BB}+\mathrm{BNP}$ normalised SERCA2a, NCX and S100A1 expression, and the phosphorylation of PLB and RyR2 (table 4, see online supplementary figure S3). The benefits of $\mathrm{BB}$ were therefore enhanced by BNP, with an additional decrease in NCX1 expression and the P-RyR2 to RyR2 ratio, and normalisation of PLB phosphorylation. These results accounted for the improved control of $\mathrm{Ca}^{2+}$ leakage and inotropy, and prevention of irregu$\operatorname{lar} \mathrm{Ca}^{2+}$ waves.

\section{DISCUSSION}

$\beta$-Blockers are commonly used as first-line treatment after MI and heart failure, with unquestionable benefits on mortality. ${ }^{14}$ Here, we conclude that a combination of the selective BB metoprolol with subcutaneous BNP is more effective to prevent cardiac remodelling than metoprolol alone in decompensated heart failure. We also provide novel insights into how the combination prevents $\mathrm{Ca}^{2+}$-handling alterations and subsequent morbid arrhythmias (figure 6). 
Table $4 \mathrm{Ca}^{2+}$-handling proteins

\begin{tabular}{|c|c|c|c|c|c|}
\hline & Sham & PMI & BNP-PMI & BB-PMI & BB-BNP-PMI \\
\hline SERCA2a (/GAPDH) & $0.51 \pm 0.12$ & $0.25 \pm 0.05^{*}$ & $0.24 \pm 0.09 *$ & $0.70 \pm 0.05^{*}, \|$ & $0.84 \pm 0.04 \dagger, \|$ \\
\hline NCX1 (/GAPDH) & $0.38 \pm 0.02$ & $0.67 \pm 0.02 \dagger$ & $0.61 \pm 0.02 \dagger$ & $0.52 \pm 0.02 *, \S$ & $0.43 \pm 0.04 \|, 9$ \\
\hline S100A1 (/GAPDH) & $0.85 \pm 0.07$ & $0.59 \pm 0.06 t$ & $0.49 \pm 0.03 \ddagger$ & $0.72 \pm .041 \|$ & $0.69 \pm 0.03 \|$ \\
\hline PSer16-PLB (/GAPDH) & $1.00 \pm 0.03$ & $0.54 \pm 0.01 *$ & $0.70 \pm 0.01 *$ & $1.53 \pm 0.02 \dagger, \S$ & $0.83 \pm 0.02$ \\
\hline PLB (/GAPDH) & $2.01 \pm 0.03$ & $2.51 \pm 0.02 *$ & $2.42 \pm 0.02$ * & $2.12 \pm 0.04 \S$ & $1.64 \pm 0.02 *, \|, \#$ \\
\hline PSer16-PLB to PLB ratio & $0.49 \pm 0.01$ & $0.17 \pm 0.02 \dagger$ & $0.20 \pm 0.01 \dagger$ & $0.72 \pm 0.01 \dagger, \S$ & $0.53 \pm 0.03 \|, \#$ \\
\hline Pser2808-RyR (/GAPDH) & $0.53 \pm 0.04$ & $0.47 \pm 0.06$ & $0.57 \pm 0.09$ & $0.48 \pm 0.05$ & $0.24 \pm 0.04$ \\
\hline RyR (/GAPDH) & $0.48 \pm 0.04$ & $0.35 \pm 0.05^{*}$ & $0.61 \pm 0.09 \S$ & $0.62 \pm 0.05^{*}, \S$ & $0.48 \pm 0.03^{*}, \S, \#$ \\
\hline Pser2808-RyR to RyR ratio & $1.12 \pm 0.09$ & $1.51 \pm 0.10^{*}$ & $1.20 \pm 0.08$ & $0.73 \pm 0.03 *, \|$ & $0.43 \pm 0.07 t, 9, \#$ \\
\hline
\end{tabular}

\section{Higher benefits of $\mathrm{BB}+\mathrm{BNP}$ on cardiac remodelling}

Favourable effects of BNP have been reported in hypertension-induced heart failure, ${ }^{15}$ but they are still debated in postischaemic heart failure. ${ }^{16-18}$ We showed that subcutaneous BNP was beneficial when combined with metoprolol in ischaemic heart failure. Furthermore, the overall benefit was independent of heart rate and haemodynamic changes. In particular, no severe hypotension was observed. ${ }^{4}$ The combination clearly associated the antifibrotic effect of BNP and the antiremodelling action of metoprolol that account for efficient antiarrhythmic properties. Even if in the ASCEND-HF trial almost $60 \%$ of patients received $\beta$-blocker therapy and/or ACE inhibitors with intravenous BNP infusion, ${ }^{4}$ it is the first time that a study specifically addressed the utility to use subcutaneous BNP associated with oral metoprolol in heart failure and reveals beneficial effects. In the ASCEND-HF trial no benefit was observed. The discrepancy may reflect differences of dosage, administration route (intravenous $0.01 \mu \mathrm{g} / \mathrm{kg} / \mathrm{min}$ for $24 \mathrm{~h}$ or more for up to 7 days in acute decompensated heart failure vs subcutaneous $0.03 \mu \mathrm{g} / \mathrm{kg} / \mathrm{min}$ for 15 days in established chronic heart failure) and of model.

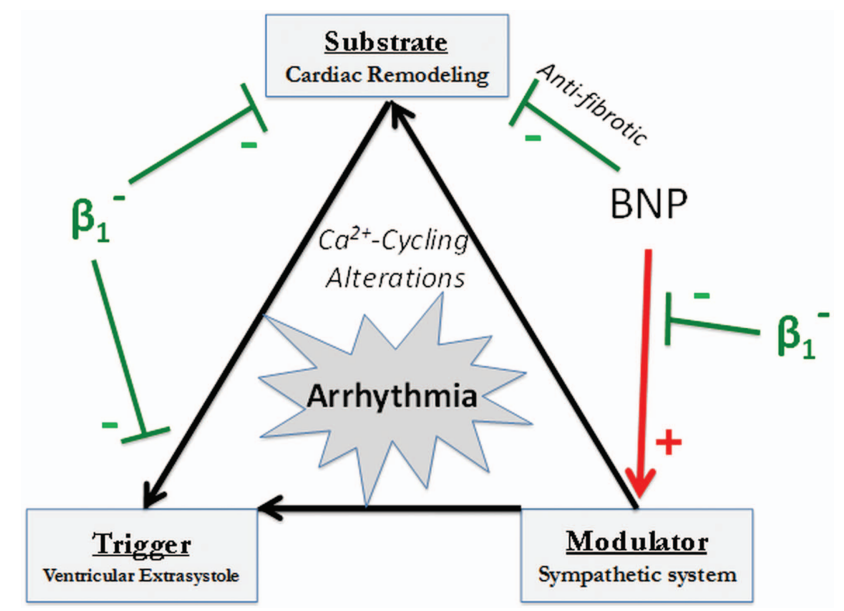

Figure 6 Beneficial effect of combination therapy in the concept of Coumel's triangle of arrhythmogenesis. ${ }^{30}$ In addition to its beneficial effects on the 'substrate' (cardiac remodelling) and the 'trigger' $\left(\mathrm{Ca}^{2+}\right.$ cycling), $\beta 1$-adrenergic receptor antagonism also abolishes the adverse consequences of B-type natriuretic peptide (BNP) on the 'modulator' (sympathetic system overactivation).
The normalisation of the sympatho-vagal balance by the combination was a key mechanism contributing to its overall therapeutic effect. Metoprolol not only provided its wellknown benefits, but it broke the deleterious loop linking BNP and sympathetic overdrive. ${ }^{3}$ Indeed, BNP promotes adrenergic signalling through two distinct pathways. BNP induces norepinephrine release from sympathetic cardiac neurons via protein kinase G-induced inhibition of PDE3-mediated cAMP hydrolysis, ${ }^{7}$ which is likely to offset its desirable effects. ${ }^{7} 819$ BNP also inhibits PDE3 through the activation of NPR-B,${ }^{8}{ }^{20}$ which is the predominant natriuretic peptide receptor in failing hearts. ${ }^{21}$ Moreover, whereas low doses of nesiritide have beneficial effect on autonomic nervous system, high doses of intravenous BNP could induce prolonged hypotension and activate the sympathetic system. ${ }^{5} 22$ Altogether, these effects could account for the increased propensity of BNP-PMI mice to develop catecholamines-induced VT, fibrillation and death. Such pro-arrhythmic effect was observed in patients in whom high doses of intravenous nesiritide induced a minor increase of VA (ventricular tachcardia (VT), couplets and triplets). ${ }^{23}$ However, in this study, the antiarrhythmic treatment of patients may have prevented the effect of parenteral vasoactive therapy on the occurrence of VAs. ${ }^{23}$ In addition, non-sustained VT was also reported during study drug infusion of nesiritide in three patients receiving a high dose of nesiritide $(0.03 \mu \mathrm{g} / \mathrm{kg} / \mathrm{min})$ in clinical trial. ${ }^{22}$ We therefore propose that the combination retains the beneficial effects of subcutaneous BNP but attenuates the deleterious consequences mediated by $\beta 1$-adrenergic pathway. In line, the combination reduced fibrosis and corrected the QRS lengthening and QT dispersion, which both correlate with a lowered risk of developing VA. ${ }^{11} 24$ Importantly, this antiarrhythmic benefit persisted over time, and lasted longer than that of metoprolol alone, which is in line with a protective long-term anti-remodelling effect.

\section{Mechanisms of higher benefits of $\mathrm{BB}+\mathrm{BNP}$ combination therapy}

Alterations in $\mathrm{Ca}^{2+}$ homeostasis are responsible for excitationcontraction coupling defects and VA. ${ }^{2}$ Aberrant ryanodine receptor (RyR) opening in diastole, observed functionally as the abnormal occurrence of $\mathrm{Ca}^{2+}$ sparks, generates spontaneous irregular $\mathrm{Ca}^{2+}$ waves involved in the triggering of VA/SVT. ${ }^{25}{ }^{26}$ Increase in $\mathrm{Ca}^{2+}$ sparks frequency could result from increased cytosolic $\mathrm{Ca}^{2+}$ level due to a blunted SERCA2a activity, associated with a modulation of the intrinsic properties of the RyR2 complex (see online 
supplement). Sympathetic overdrive, leading to SR-Ca ${ }^{2+}$ leakage, may be involved since high diastolic $\mathrm{Ca}^{2+}$ levels could also participate in the triggering of afterdepolarisations. The combination effectively reduced SR-Ca ${ }^{2+}$ leakage, and improved SR-Ca ${ }^{2+}$ load and transient amplitude by normalising proteins alterations which accounted for the maintained cell contraction and the antiarrhythmic properties. Interestingly, the combination restored baseline levels of S100A1 and increased SR-Ca ${ }^{2+}$ content. Restoration of S100A1 expression, as a $\mathrm{Ca}^{2+}$-dependent molecular inotrope regulating cardiac SR-Ca ${ }^{2+}$ cycling, was suggested to treat heart failure. $^{27}$

\section{Clinical implication}

The most important finding of this study is that association of oral metoprolol with subcutaneous BNP infusion is more effective than monotherapy with the $\beta$-blocker in reducing ventricular remodelling and VA following MI. The interest of combinations, elevating circulating plasma concentration of natriuretic peptides associated with classical drugs, has been recently highlighted. ${ }^{28} 29$ For example, neutral endopeptidase inhibitors have per se limited clinical benefice. However, their association with ACE or angiotensin receptor antagonists is promising despite limitations such as incidence of multilevel potentially life-threatening angioedema. ${ }^{28}$ Our results may challenge this innovative concept because $\beta 1$-adrenergic receptor antagonisation abolished the main adverse effects of BNP (figure 6). The therapeutic benefits resulted from an improved balance of the BNP and adrenergic systems, and from mechanisms intrinsic to the two pathways at the cardiomyocytes level. These promising results obtained in an experimental model of ischaemic heart failure warrant further evaluation and optimisation (dose) in humans.

\section{Key messages}

\section{What is already known on this subject}

Chronic B-type natriuretic peptide (BNP) administration alters excitation-contraction coupling $\left(\mathrm{Ca}^{2+}\right.$ signalling) in mouse ventricular cardiomyocytes, which triggers ventricular arrhythmia through activation of the sympathetic system. However, chronic subcutaneous BNP improves cardiac function and avoids the severe hypotensive effect of BNP.

\section{What this study adds}

We determined the effects of a combination of the selective $\beta 1$-adrenergic blocker metoprolol associated with subcutaneous BNP infusion in a mouse model of decompensated heart failure. Until now, no study in humans or animals had specifically tested this combination and investigated both cellular and molecular mechanisms. We showed that metoprolol unmasks beneficial effects of BNP. The combination of the two molecules reduced the occurrence of both spontaneous and catecholamines-induced ventricular tachycardia in postischaemic heart failure.

Contributors (1) Conception and design or analysis and interpretation of data, or both, in addition to experimental work: JT, SK, SR, JR, CC, AG, JF, FA. (2) Drafting of the manuscript or revising it critically for important intellectual content: JT DB, J-Y LG, AL, SR. (3) Final approval of the manuscript submitted: JT, SR.

Funding This work was supported by Fondation de France (Project PepNaRhythm, $N^{\circ}$ 2068001722) and INSERM. JT, SR, JF and AL hold CNRS positions.

Competing interests None.

Provenance and peer review Not commissioned; externally peer reviewed.

\section{REFERENCES}

1 Roger VL, Go AS, Lloyd-Jones DM, et al. Heart disease and stroke statistics-2012 update: a report from the American Heart Association. Circulation 2012;125: e2-220.

2 Ikeda Y, Hoshijima M, Chien KR. Toward biologically targeted therapy of calcium cycling defects in heart failure. Physiology (Bethesda) 2008;23:6-16.

3 Thireau J, Karam S, Fauconnier J, et al. Functional evidence for an active role of B-type natriuretic peptide in cardiac remodelling and pro-arrhythmogenicity. Cardiovasc Res 2012:95:59-68.

$4 \mathrm{O}^{\prime}$ Connor CM, Starling RC, Hernandez AF, et al. Effect of nesiritide in patients with acute decompensated heart failure. N Engl J Med 2011;365:32-43.

5 Aronson D, Burger AJ. Effect of nesiritide (human b-type natriuretic peptide) and dobutamine on heart rate variability in decompensated heart failure. Am Heart $J$ 2004;148:e16.

6 Azevedo ER, Newton GE, Parker AB, et al. Sympathetic responses to atrial natriuretic peptide in patients with congestive heart failure. J Cardiovasc Pharmacol 2000;35:129-35.

7 Chan NY, Seyedi N, Takano K, et al. An unsuspected property of natriuretic peptides: promotion of calcium-dependent catecholamine release via protein kinase G-mediated phosphodiesterase type 3 inhibition. Circulation 2012;125:298-307.

8 Qvigstad E, Moltzau LR, Aronsen JM, et al. Natriuretic peptides increase beta1-adrenoceptor signalling in failing hearts through phosphodiesterase 3 inhibition. Cardiovasc Res 2010;85:763-72.

9 Chen HH, Glockner JF, Schirger JA, et al. Novel protein therapeutics for systolic heart failure: chronic subcutaneous B-type natriuretic peptide. J Am Coll Cardiol 2012;60:2305-12

10 Hunt SA, Abraham WT, Chin MH, et al. ACC/AHA 2005 Guideline Update for the Diagnosis and Management of Chronic Heart Failure in the Adult: a report of the American College of Cardiology/American Heart Association Task Force on Practice Guidelines (Writing Committee to Update the 2001 Guidelines for the Evaluation and Management of Heart Failure): developed in collaboration with the American College of Chest Physicians and the International Society for Heart and Lung Transplantation: endorsed by the Heart Rhythm Society. Circulation 2005;112: e154-235

11 Bonnar CE, Davie AP, Caruana L, et al. QT dispersion in patients with chronic heart failure: beta blockers are associated with a reduction in QT dispersion. Heart 1999;81:297-302

12 Volkers M, Loughrey CM, Macquaide N, et al. S100A1 decreases calcium spark frequency and alters their spatial characteristics in permeabilized adult ventricular cardiomyocytes. Cell Calcium 2007:41:135-43.

13 Most P, Remppis A, Pleger ST, et al. S100A1: a novel inotropic regulator of cardiac performance. Transition from molecular physiology to pathophysiological relevance. Am J Physiol Regul Integr Comp Physiol 2007;293:R568-77

14 Antman EM, Hand M, Armstrong PW, et al. 2007 Focused Update of the ACC/AHA 2004 Guidelines for the Management of Patients With ST-Elevation Myocardial Infarction: a report of the American College of Cardiology/American Heart Association Task Force on Practice Guidelines: developed in collaboration With the Canadian Cardiovascular Society endorsed by the American Academy of Family Physicians: 2007 Writing Group to Review New Evidence and Update the ACC/AHA 2004 Guidelines for the Management of Patients With ST-Elevation Myocardial Infarction, Writing on Behalf of the 2004 Writing Committee. Circulation 2008; 117:296-329

15 Cataliotti A, Tonne JM, Bellavia D, et al. Long-term cardiac pro-B-type natriuretic peptide gene delivery prevents the development of hypertensive heart disease in spontaneously hypertensive rats. Circulation 2011;123:1297-305.

16 Pan $Y$, Zhu W, Ma J, et al. Therapeutic effects of continuous infusion of brain natriuretic peptides on postmyocardial infarction ventricular remodelling in rats. Arch Cardiovasc Dis 2011;104:17-28.

17 He J, Chen Y, Huang Y, et al. Effect of long-term B-type natriuretic peptide treatment on left ventricular remodeling and function after myocardial infarction in rats. Eur J Pharmacol 2009;602:132-7.

18 George I, Xydas S, Klotz S, et al. Long-term effects of B-type natriuretic peptide infusion after acute myocardial infarction in a rat model. J Cardiovasc Pharmacol 2010:55:14-20.

19 Chan NY, Robador PA, Levi R. Natriuretic peptide-induced catecholamine release from cardiac sympathetic neurons: inhibition by histamine $\mathrm{H} 3$ and $\mathrm{H} 4$ receptor activation. J Pharmacol Exp Ther 2012:343:568-77.

20 Springer J, Azer J, Hua R, et al. The natriuretic peptides BNP and CNP increase heart rate and electrical conduction by stimulating ionic currents in the sinoatrial node and atrial myocardium following activation of guanylyl cyclase-linked natriuretic peptide receptors. J Mol Cell Cardiol 2012;52:1122-34.

21 Dickey DM, Flora DR, Bryan PM, et al. Differential regulation of membrane guanylyl cyclases in congestive heart failure: natriuretic peptide receptor (NPR)-B, Not NPR-A, is the predominant natriuretic peptide receptor in the failing heart. Endocrinology 2007; 148:3518-22.

22 Mills RM, LeJemtel TH, Horton DP, et al. Sustained hemodynamic effects of an infusion of nesiritide (human b-type natriuretic peptide) in heart failure: a 
randomized, double-blind, placebo-controlled clinical trial. Natrecor Study Group. J Am Coll Cardiol 1999;34:155-62.

23 Burger AJ, Horton DP, LeJemtel T, et al. Effect of nesiritide (B-type natriuretic peptide) and dobutamine on ventricular arrhythmias in the treatment of patients with acutely decompensated congestive heart failure: the PRECEDENT study. Am Heart J 2002;144:1102-8.

24 Hinterseer M, Beckmann BM, Thomsen MB, et al. Usefulness of short-term variability of QT intervals as a predictor for electrical remodeling and proarrhythmia in patients with nonischemic heart failure. Am J Cardiol 2010;106:216-20.

25 Cheng H, Lederer WJ. Calcium sparks. Physiol Rev 2008;88:1491-545.

26 Fauconnier J, Thireau J, Reiken S, et al. Leaky RyR2 trigger ventricular arrhythmias in Duchenne muscular dystrophy. Proc Natl Acad Sci U S A 2010;107:1559-64.
27 Brinks $\mathrm{H}$, Rohde $\mathrm{D}$, Voelkers $\mathrm{M}$, et al. S100A1 genetically targeted therapy reverses dysfunction of human failing cardiomyocytes. J Am Coll Cardiol 2011:58:966-73.

28 Mangiafico S, Costello-Boerrigter LC, Andersen IA, et al. Neutral endopeptidase inhibition and the natriuretic peptide system: an evolving strategy in cardiovascular therapeutics. Eur Heart J 2013;34:886-93C.

29 von Lueder TG, Sangaralingham SJ, Wang BH, et al. Renin-Angiotensin blockade combined with natriuretic Peptide system augmentation: novel therapeutic concepts to combat heart failure. Circ Heart Fail 2013; 6:594-605.

30 Coumel P. Cardiac arrhythmias and the autonomic nervous system. I Cardiovasc Electrophysiol 1993:4:338-55. 